\title{
Laparoscopic bowel resection combined with hand-assisted endoscopic balloon dilation for Crohn's disease with multiple bowel strictures
}

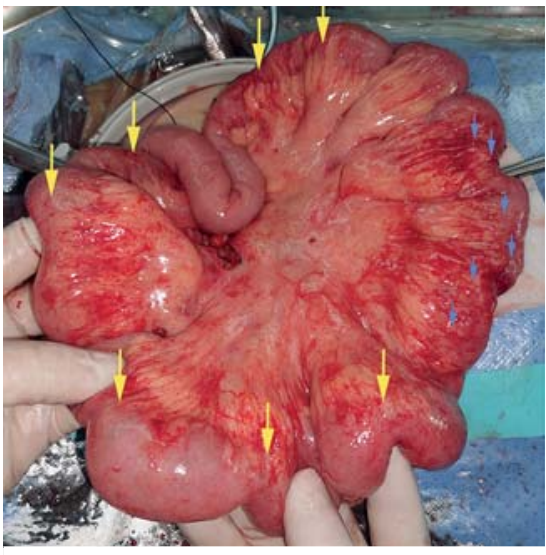

Fig. 1 Intraoperative view showing 13 intermittent short stenoses (yellow arrows) and a long stenotic lesion (blue arrows).

Stricturoplasty is a common surgical technique for patients with multiple bowel obstruction caused by Crohn's disease [1-3], Here, we present an innovative case of hand-assisted laparoscopic bowel resection combined with hand-assisted endoscopic balloon dilation (EBD).

A 25-year-old woman with 7-year history of Crohn's disease presented with an ileo-abdominal wall fistula and incomplete ileus. A hand-assisted laparoscopic approach was used to make a 6-cm exploratory incision. This revealed, besides
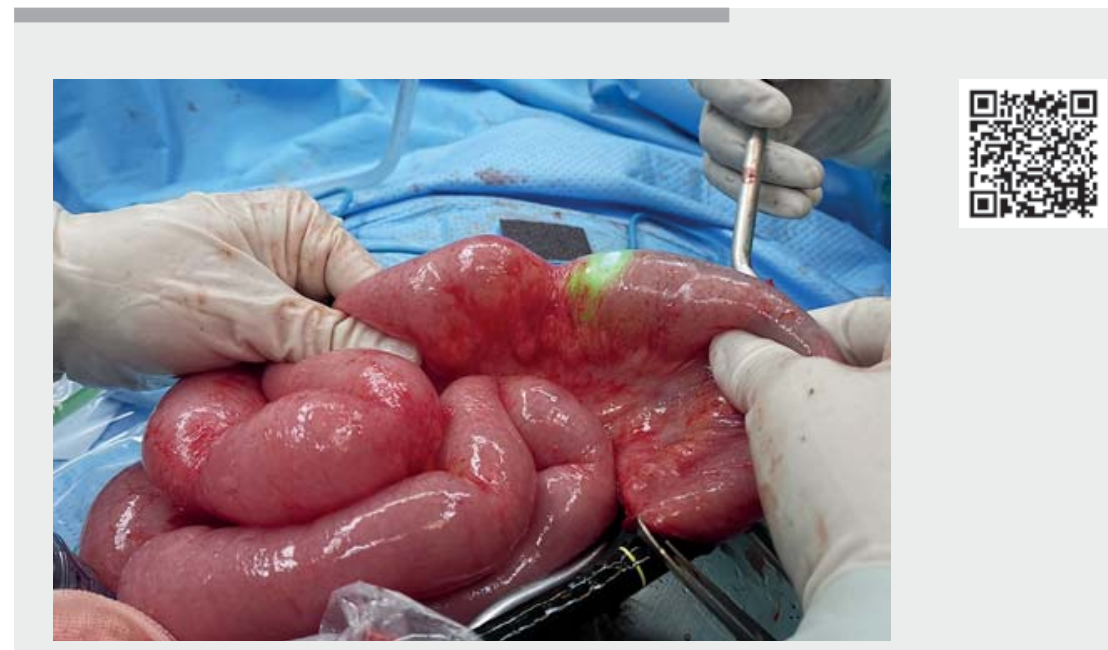

Video 1 One to two dilations were performed for each stricture until the colonoscope could be adequately passed through the bowel. After being repeated for all 13 strictures, no active bleeding or perforation was observed under backward checking.

the ileocolic fistulous lesion, 13 short stenoses $(<2 \mathrm{~cm})$ sequentially distributed within the segment of bowel $230 \mathrm{~cm}$ to $520 \mathrm{~cm}$ from the ligament of Treitz, and also a longer stenotic lesion $(20 \mathrm{~cm}$ in length) at $400 \mathrm{~cm}$ ( $\mathbf{F i g . 1}$ ). Still with the hand-assisted laparoscopic approach, the ileocolic fistula was detached from the abdominal wall, then the ileocolic and $20-\mathrm{cm}$ ileal lesion were resected (> Fig. 2).
A colonoscope (Olympus PCF Q260J) was inserted through the proximal cut edge, into the upstream small intestine ( Fig.3). The surgeon pushed the endoscope near the stenosis and adjusted the angle and position of the probe. The pressure of EBD (12-mm and 14-mm balloon; Cook Medical, USA) was maintained for between 30 seconds and 1 minute, with the deflation being performed according to surgeon's opinion of the change in
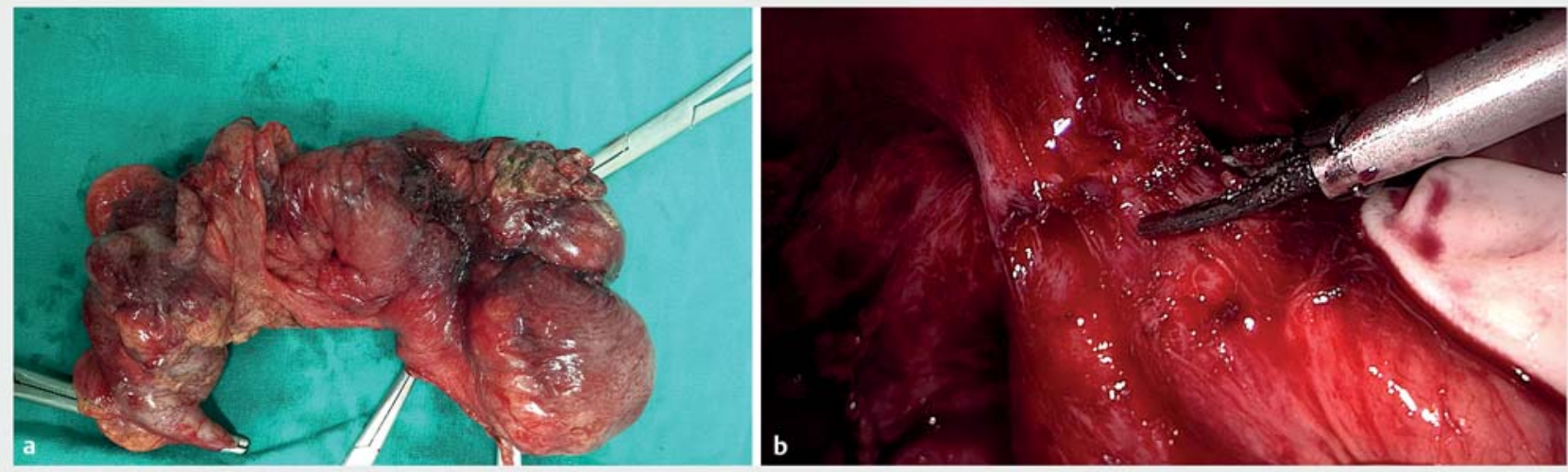

Fig. 2 The ileocolic lesion with the ileo-abdominal wall fistula was resected under hand-assisted laparoscopic approach. 

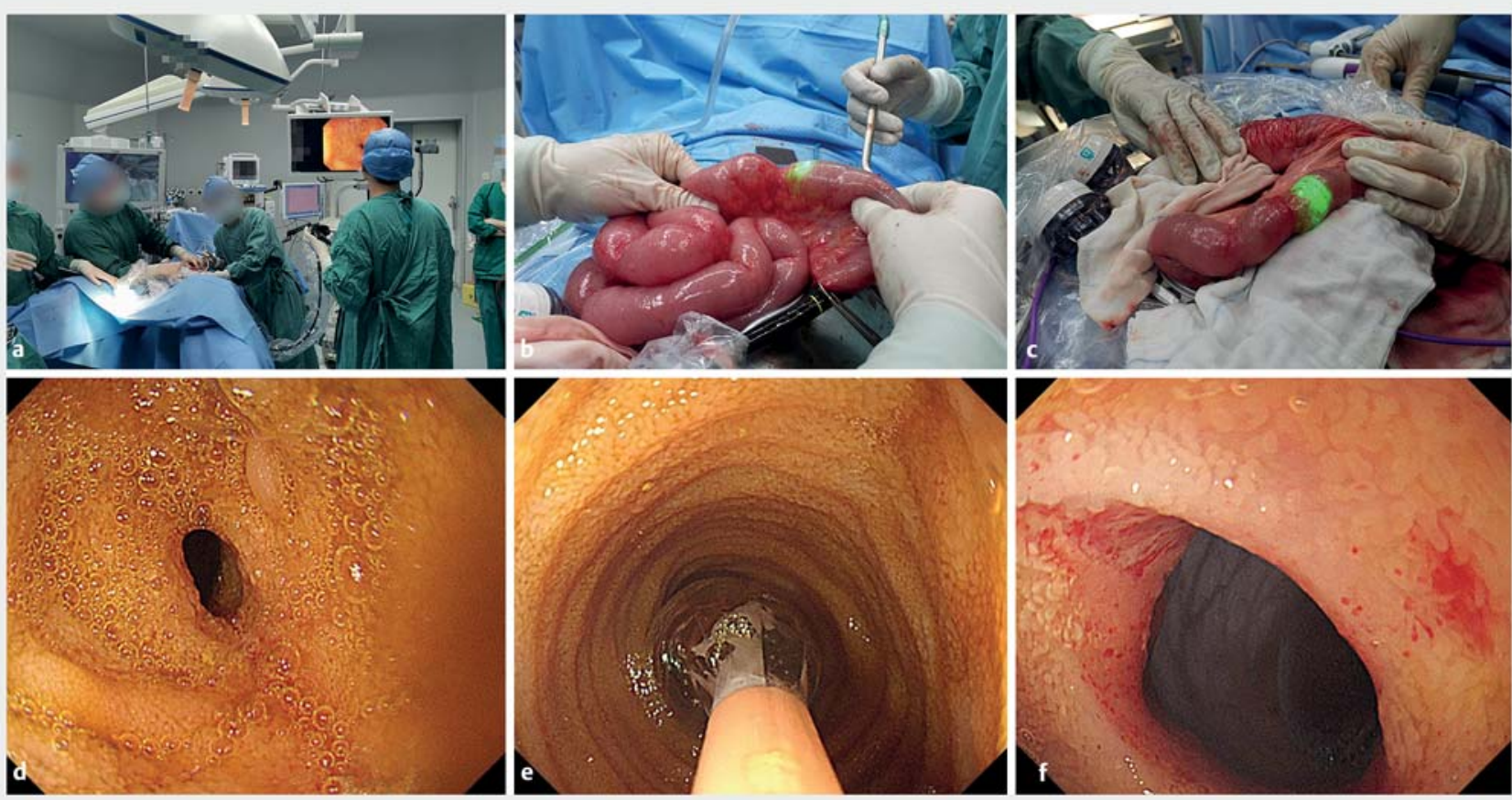

- Fig. 3 Images during the hand-assisted endoscopic balloon dilation (EBD) procedures showing: a repeated EBDs being performed with hand assistance from the surgeon; $\mathbf{b}$ the endoscope being pushed near to a stenosis and held in place by hand; $\boldsymbol{c}$ the endoscope passing the stricture following the dilation procedure; $\mathbf{d}-\mathbf{f}$ endoscopic view of one of the strictures before and after EBD.
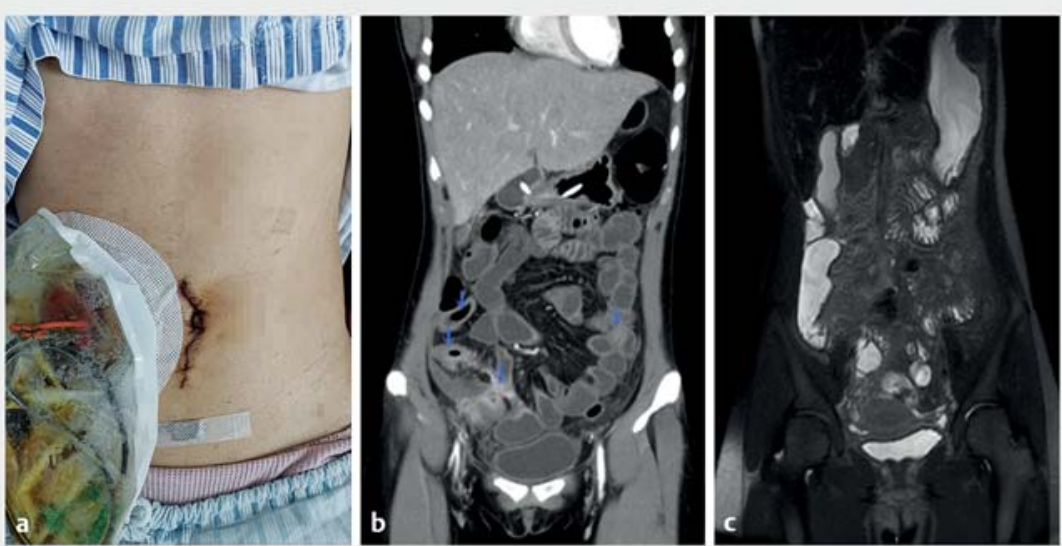

Fig. 4 The patient recovered well with improvement in the stenoses as shown by: a recovery of bowel function 3 days after surgery, with the 6 -cm incision visible besides the ileostomy; $\mathbf{b}$ preoperative computed tomography enterography images revealing multiple strictures (blue arrows); $c$ the postoperative magnetic resonance enterography 4.5 months later, which showed no evidence of stenosis or lumen dilatation.

lumen thickness. One to two dilations were performed for each stricture until the colonoscope was able to adequately pass through. After repetition for the 13 strictures, no active bleeding or perforation was observed under backward checking ( $\vee$ Fig. 3 ; $\triangleright$ Video 1$)$. A side-to- side anastomosis was then made for the $20-\mathrm{cm}$ lesion and a loop stoma was made at the terminal ileum. Post-operatively, after 10 days of fasting, the amount of enteral nutrition was gradually increased. On comparison with the preoperational computed tomography enterography, no stenosis or lumen dilation were found on postoperative magnetic resonance enterography performed 4.5 months later ( Fig. 4).

Hand-assisted laparoscopic bowel resection combined with hand-assisted EBD could be applied on more extensively distributed stenoses, more safely and precisely.

Endoscopy_UCTN_Code_TTT_1AT_2AF

Competing interests

The authors declare that they have no conflict of interest.

The authors

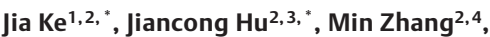
Wei Wang ${ }^{2,4}$, Ping $\operatorname{Lan}^{1,2}$, Xiaojian Wu ${ }^{1,2}$, Min Zhi' ${ }^{2,4}$

1 Department of Colorectal Surgery, The Sixth Affiliated Hospital, Sun Yat-sen University, Guangzhou, Guangdong Province, China

2 Guangdong Institute of Gastroenterology, Guangdong Province Key Laboratory of 
Colorectal and Pelvic Floor Diseases, Guangzhou, Guangdong Province, China

3 Ambulatory Surgery Center, The Sixth Affiliated Hospital, Sun Yat-sen University, Guangzhou, Guangdong Province, China

4 Department of Gastroenterology, The Sixth Affiliated Hospital, Sun Yat-sen University, Guangzhou, Guangdong Province, China

\section{Corresponding author}

\section{Min Zhi, MD}

The Sixth Affiliated Hospital, Sun Yat-sen University, 26 Yuancun Erheng Road, Tianhe District, Guangzhou 510655, Guangdong Province, China

zhimin@mail.sysu.edu.cn

\section{References}

[1] Lightner AL, Vogel JD, Carmichael JC et al. The American Society of Colon and Rectal Surgeons clinical practice guidelines for the surgical management of Crohn's disease. Dis Colon Rectum 2020; 63: 1028-1052

[2] Kanamori A, Sugaya T, Tominaga K et al. Endoscopic balloon dilation for stenotic lesions in Crohn's disease. Turk J Gastroenterol 2017; 28: 117-124

[3] Navaneethan U, Lourdusamy V, Njei B et al. Endoscopic balloon dilation in the management of strictures in Crohn's disease: a systematic review and meta-analysis of nonrandomized trials. Surg Endosc 2016; 30 : 5434-5443

Bibliography

Endoscopy 2022; 54: E242-E244

DOI 10.1055/a-1472-7532

ISSN 0013-726X

published online 8.6.2021

(c) 2021. Thieme. All rights reserved.

Georg Thieme Verlag KG, Rüdigerstraße 14,

70469 Stuttgart, Germany
ENDOSCOPY E-VIDEOS

https://eref.thieme.de/e-videos



Endoscopy E-Videos is an open access online section, reporting on interesting cases and new techniques in gastroenterological endoscopy. All papers include a high quality video and all contributions are freely accessible online. Processing charges apply (currently EUR 375), discounts and wavers acc. to HINARI are available.

This section has its own submission website at

https://mc.manuscriptcentral.com/e-videos

\footnotetext{
* Equal first authors
} 